\title{
Uniform Field Emission from Carbon Nanotubes Fabricated by CO Disproportionation
}

\author{
Jin Seung Lee and Jung Sang Suh \\ School of Chemistr. Seoul National Cniversity, Seoul 151-747, Korea \\ Received November 10, 2003
}

\begin{abstract}
Field emission of carbon nanotubes (CNTs) fabricated by disproportionation of CO has been studied. CNTs fabricated on well-ordered Co nanowire arrays formed on the porous anodic aluminum oxide templates were well graphitized. uniform in diameter and aligned vertically with respect to the plane of the template. and showed a good field emission property. Very unifonm emissions were observed from the CNTs fabricated at relatively low temperature. $500-600^{\circ} \mathrm{C}$. Low fabrication temperature such as $500^{\circ} \mathrm{C}$ could make it possible to fabricate CNTs on soda lime glass. a low-cost substrate. for displaỵ panel.
\end{abstract}

Key Words : Carbon nanotube. Anodic aluminum oxide, Carbon monoxide, Field enission

\section{Introduction}

Carbon nanotubes (CNTs) have recently attracted considerable interest because of their unique properties and potential applications. ${ }^{1-3}$ CNTs are promising for field enission applications since they have excellent field emission properties such as high aspect ratio. high chemical stability. high thermal conductivity. and high mechanical strength. ${ }^{l}$

There have been many reports on field emission of CNTs but only a few reports have showed field enission patterns and they are not homogeneous. ${ }^{3-9}$

$\mathrm{CO}$ has been used as a carbon source in synthesis of CNTs. ${ }^{10-12}$ When the disproportionation of $\mathrm{CO}$, i.e. the Boudouard reaction occurs on metal surface, only $\mathrm{C}$ and $\mathrm{CO}_{2}$ are produced ${ }^{13} \mathrm{CO}_{2}$ is a very stable gas and desorbs from the surface without further reaction. Therefore. the Boudouard reaction can provide pure carbon as a carbon source in synthesizing CNTs.

The CNTs fabricated by disproportionation of $\mathrm{CO}$ in previous were not aligned $d^{6-12}$ or contaminated the surface of the aligned $\mathrm{CNTs}^{14}$ and no field emission property of them has been reported. Recently we have succeeded to fabricate. without contamination, aligned CNTs by disproportionation of $\mathrm{CO}$. using $\mathrm{Co}$ nanowire arrays formed in an AAO template and reported the field emission property. ${ }^{15}$ The field enission has been very uniform. The CNTs has been fabricated at $600{ }^{\circ} \mathrm{C}$. This temperature is higher than the melting point of soda lime glass $\left(550^{\circ} \mathrm{C}\right)$ that is a low-cost substrate for display panel. Therefore, it may be necessary to study the field emission properties of the CNTs fabricated at a lower temperature, by $\mathrm{CO}$ disproportionation.

Here, we report the field emission properties of aligned CNTs fabricated at $500-600^{\circ} \mathrm{C}$ by disproportionation of $\mathrm{CO}$. using $\mathrm{Co}$ nanowire arrays formed in an $\mathrm{AAO}$ template.

\footnotetext{
Author to whom comespondence should be addressed. Fax: +822-889-0749, e-mail: jssulnatcplaza.snu. ac.kr
}

\section{Experimental Section}

The method to prepare ordered AAO templates using a two-step anodization technique ${ }^{15}$ has been published. ${ }^{14.17 .18}$ A second anodization was performed in a $0.3 \mathrm{M}$ oxalic acid solution at $17^{\circ} \mathrm{C}$ by applying $40 \mathrm{VDC}$ for $5 \mathrm{~min}$ and then a voltage drop from $40 \mathrm{~V}$ to $18 \mathrm{~V}$ was done. The pore depth was about $660 \mathrm{~mm}$. Co was deposited near to the mouth of the pores of the templates at $13.5 \mathrm{~V}$. After the deposition of $\mathrm{Co}$. the template was dipped into $0.01 \mathrm{M}$ sulfuric acid for 30 $s$ and then $0.1 \mathrm{~m} \mathrm{NaOH}$ solution for $90 \mathrm{~s}$.

After placing the template in a tube furnace. CNTs were fabricated by flowing carbon monoxide $(100 \mathrm{~mL} / \mathrm{min})$ at 500.550 and $600^{\circ} \mathrm{C}$ for 12 hour. Fabricated templates and CNTs were analyzed by using a scanning electron microscopy (SEM: Philips FEG XL. $30 \mathrm{kV}$ ). A phosphor coated indium tin oxide (ITO) glass electrode was used to monitor the electron emission pattern of the CNTs fabricated on AAO templates and to measure the emission current versus the applied voltage. The distance between the tip of the CNTs and the anode was about $200 \mathrm{~nm}$ and the pressure of the vacuum chamber was $1.6 \times 10^{-6}$ Torr.

\section{Results and Discussion}

Figure la represents a SEM image of an AAO template surface before being treated with $\mathrm{H}_{2} \mathrm{SO}_{4}$ and $\mathrm{NaOH}$ solution after $\mathrm{Co}$ electrodeposition. It is seen that $\mathrm{Co}$ metal is filled within all pores. The white dots are Co. Some of the white dots are much bigger than the pore diameter due to overdeposition. Filling Co metal near to the mouth of the pores was controlled by monitoring the electric current during the electrodeposition. When Co metal grows from the pore bottom. the current decreases monotonically except a sharp increasing at the initial stage. As soon as the pore filling has completed and overdeposition takes place, the current increases again. abruptly. The electrodeposition was stopped when the current started to increase. Figure $\mathrm{lb}$ shows a SEM image of the AAO template surface deposited 

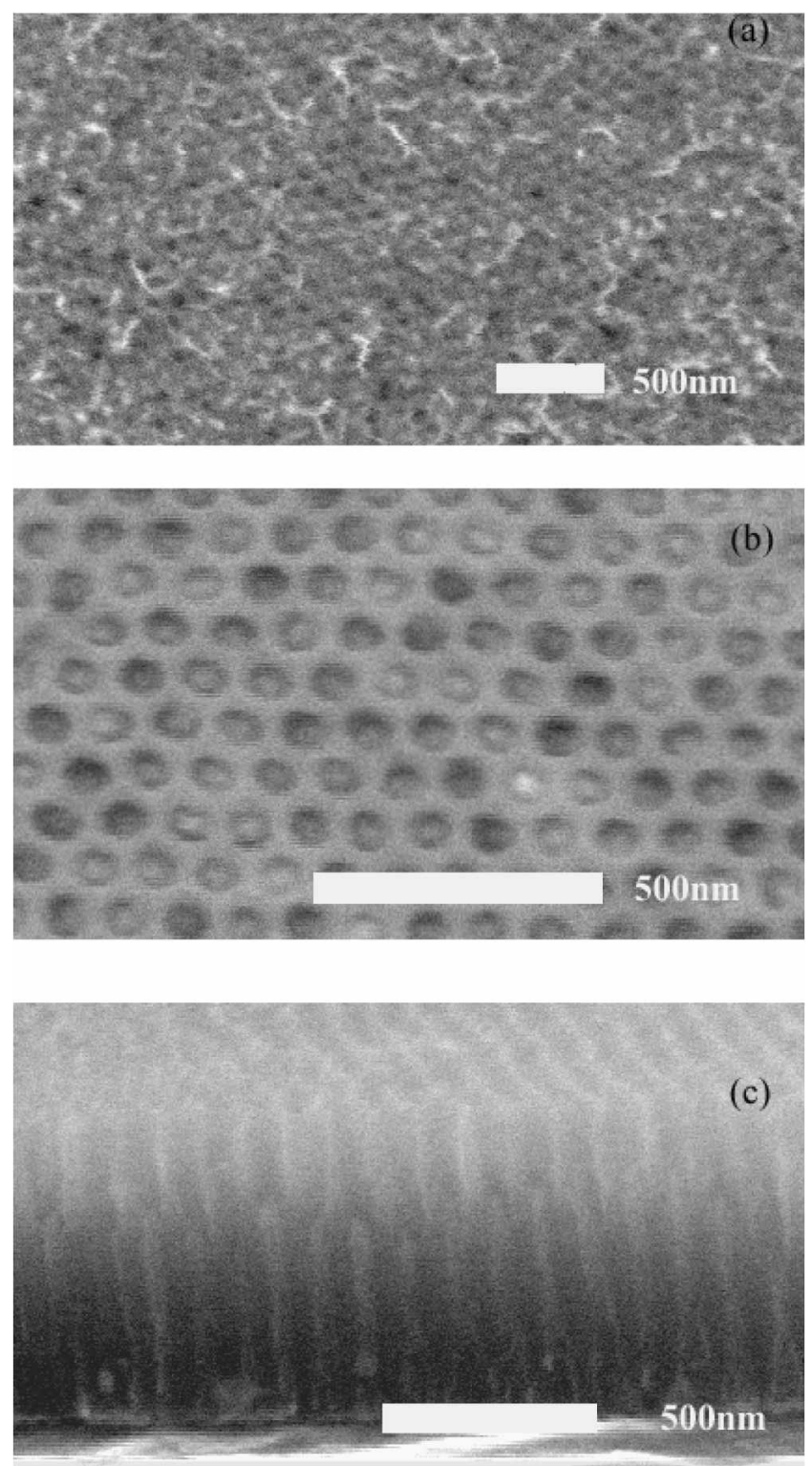

Figure 1. SEM images of an AAO template deposited $\mathrm{CO}$ : (a) the surface view after deposition of $\mathrm{CO}$, and (b) the surface and (c) a cross-sectional views after being treated with $\mathrm{H}_{2} \mathrm{SO}_{4}$ and then $\mathrm{NaOH}$ solutions. Co is about $160 \mathrm{~nm}$ below the surtace in the pores after etching in acid and base solutions.

$\mathrm{Co}$ after etching in $\mathrm{H}_{2} \mathrm{SO}_{4}$ and then $\mathrm{NaOH}$ solutions. The overdeposited $\mathrm{Co}_{0}$ was removed by dissolving in $\mathrm{H}_{2} \mathrm{SO}_{4}$ solution. Although the nanopores are slightly deformed by etching they exhibit almost a perfect 2-D array with a hexagonal pattern. Before being treated. the average diameter and interpore distance were $28.6 \pm 1.0 \mathrm{~nm}$ and $104.2 \pm 2.3$ $\mathrm{lum}$, respectively. The pore density is about $1.1 \times 10^{10}$ pores/ $\mathrm{cm}^{2}$. By using of overdeposition and etching techniques. we could prepare well-ordered Co nanowire arrays without contaminating the surface. by eliminating the mechanical polishing process. The SEM image of a cross-sectional view after being treated with $\mathrm{H}_{2} \mathrm{SO}_{4}$ and then $\mathrm{NaOH}$ solutions is shown in Figure lc. Co is about $160 \mathrm{rm}$ below the surface in the pores. This is due to the fact that the dissolving rate of
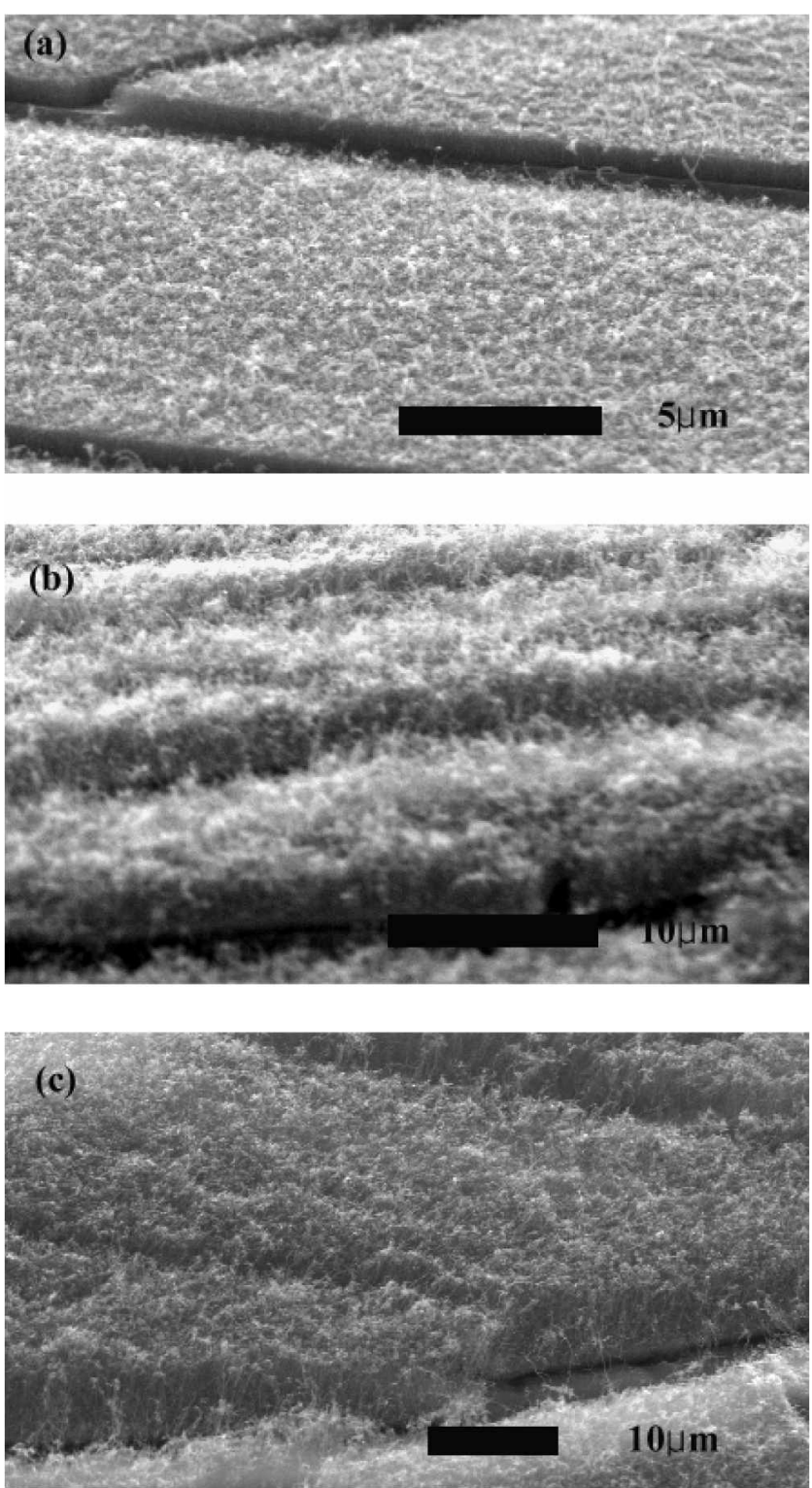

Figure 2. SEM inages of the $\mathrm{CNl}$ 's tabricated by $\mathrm{CO}$ disproportionation at (a) 500, (b) 550 , and (c) $600{ }^{\circ} \mathrm{C}$. Cracks were made intentionally to observe the side views.

the Co nanowires in sulfuric acid solution is much faster than that of alumina of the template. By etching with $\mathrm{NaOH}$ after dipping in $\mathrm{H}_{2} \mathrm{SO}_{4}$ solution. the part of each pore where no Co was filled has been widened.

Figure 2 shows SEM images of CNTs fabricated on the AAO template etched in $\mathrm{H}_{2} \mathrm{SO}_{4}$ and then $\mathrm{NaOH}$ solutions after $\mathrm{Co}$ deposition. by disproportionation of $\mathrm{CO}$ at three different temperatures: 500,550 and $600{ }^{\circ} \mathrm{C}$. Nanotubes cover the whole surface of each template. Tubes fabricated at relatively high temperature are vertically well aligned although a few appear to be tangled or curved. For the case of $500^{\circ} \mathrm{C}$, most CNTs are bundled together. By close examination. tubes are grown from all the pores. The diameters of these tubes are very uniform as $32 \mathrm{~mm}$ but the length of them increase with increasing temperature: about $0.5,2.5$ and $7 \mu \mathrm{m}$. respectively: The fabrication time was the 
same in all cases. This means that the fabrication temperature in this temperature range critically affects the growing rates of the CNTs. At $650{ }^{\circ} \mathrm{C}$, the template was deformed during fabrication although the temperature is lower than the melting point of aluminum, $660{ }^{\circ} \mathrm{C}$. By the high resolution TEM image, the CNTs were well graphitized and consisted of about 32 concentric shells of carbon sheets and their inner and outer diameters were about 10 and $32 \mathrm{~nm}$, respectively.

The CNTs in Figure 2 are grown out from the pores but they are not as ordered as the CNTs made in the pores of AAO templates. ${ }^{17}$ The CNTs forned in the pores as the shape of the pores are made by catalysis of alumina of AAO templates when hydrocarbons like acetylene are used as a precursor, ${ }^{12} \mathrm{CO}$ is not catalyzed by alumina of $\mathrm{AAO}$ templates. Therefore, the CNTs fabricated by $\mathrm{CO}$ disproportionation are made by catalysis of Co deposited in the pores. It is known that the CNTs are growing out from the pores of the AAO templates deposited Co by the tip growth mechanism. ${ }^{17}$

A well graphitization of the CNTs is supported by the Raman data (see Figure 3). The Raman bands are well developed even in the region of higher-order Raman process. The relative intensity of the $D$ band at $1353 \mathrm{~cm}^{-1}$ to the $G$ band at $1585 \mathrm{~cm}^{-1}$ is low and it decreases with increasing the fabrication temperature. The D band is known due to the disordered and small crystalline size $\mathrm{sp}^{2}$ carbons. ${ }^{20} \mathrm{lt}$ is known that the weak relative intensity of $D$ band to $G$ band indicates that the carbon nanotubes have a good graphitized structure. ${ }^{\text {la } 21}$ For most tubes fabricated by chemical vapor

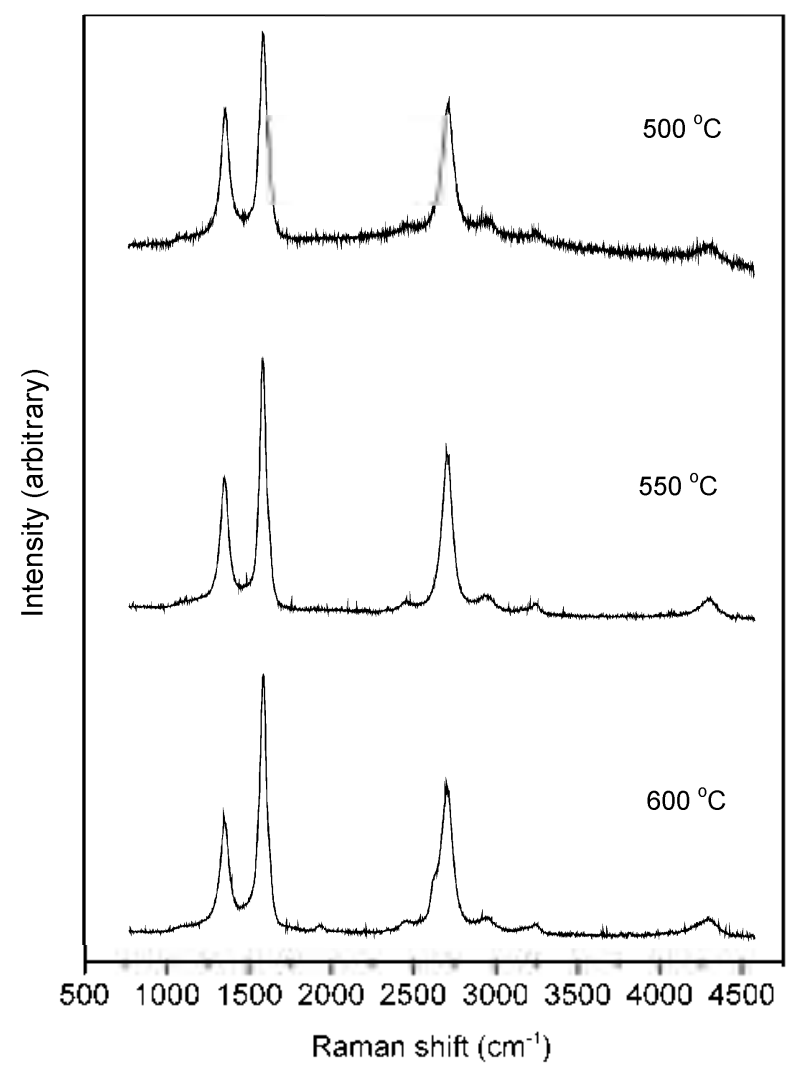

Figure 3. Raman spectra of $\mathrm{CN}^{\mathrm{N}} \mathrm{T}$ s fabricated by $\mathrm{CO}$ disproportionation at 500.550 and $600^{\circ} \mathrm{C}$. deposition (CVD), I) band is more broad and stronger than $\mathrm{G}$ band. ${ }^{20}$ It is concluded that CNTs fabricated by disproportionation of $\mathrm{CO}$ are well graphitized and the graphitization is improved by increasing fabrication temperature.

The measured emission current as function of applied voltage for samples fabricated at 500,550 and $600^{\circ} \mathrm{C}$ is shown in Figure 4. We could not measure the field emission from the CNTs fabricated at $650{ }^{\circ} \mathrm{C}$ because the template was deformed during fabrication. Current-voltage $(1-b)$ curves are relatively smooth and reproducible. The size of the sample plates were $1.0 \times 1.7-2.6 \mathrm{~cm}^{2}$. The field-emission data was analyzed using the Fowler-Nordheim model ${ }^{22}$ (Inl/ $\left.\mathrm{V}^{2}-1 / \mathrm{V}\right)$. Replotting of the data as $\ln \left(/ / \mathrm{V}^{2}\right)$ vs $1 / \mathrm{V}$ is inserted in Figure 4 and indicates the Fowler-Nordheim type field emission behavior. The enhancement factor $\beta$ is derived from the slope by assuming a work function of CNTs as 5 $\mathrm{eV}$. The $\beta$ values for CNTs fabricated at 500,550 and $600{ }^{\circ} \mathrm{C}$ are 1690,3000 , and 3520 , respectively. The $\beta$ value of CNTs fabricated at $500{ }^{\circ} \mathrm{C}$ is relatively low. This may be mainly due to the bundling of the tips of CNTs fabricated at $500^{\circ} \mathrm{C}$. These values are higher than some reported ones. ${ }^{8.23}$ The CNTs fabricated here are so dense that the field emission could be greatly decreased by the field screen effect ${ }^{2}+25$ provoked by the proximity of the neighboring tubes. Also, it is known" that the bottom barrier layer of AAO templates affects greatly to the field emission but for the samples used here the bottom barrier layer has not been removed. If one considers the field screen and bottom barrier effects, there is no doubt that the CNTs fabricated by CO disproportionation

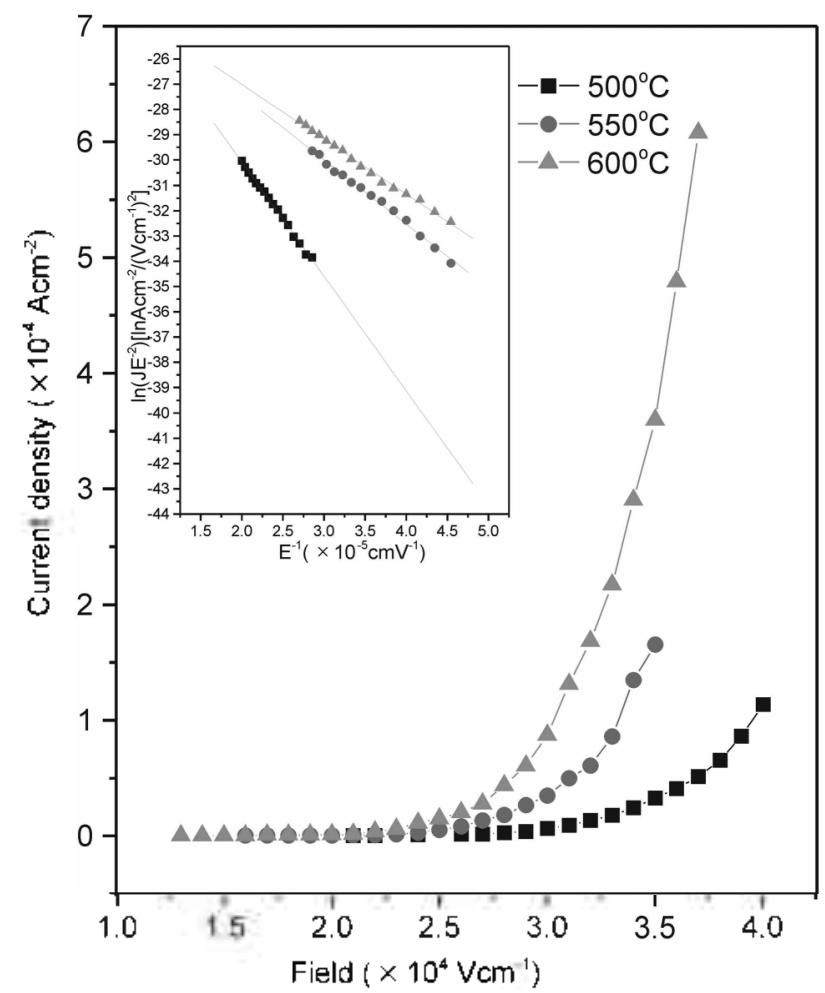

Figure 4. Jield emission curtent density ws electric lield for the C'VIs fabricated by $\mathrm{CO}$ disproportionation at 500.550 . and $600^{\circ} \mathrm{C}$. Inset is the corresponding Fowler-Nordheim plots. 
are a good field emitter.

During current density measurements. emission patterns were monitored with a phosphor screen. The CNTs fabricated at 500.550 . and $600^{\circ} \mathrm{C}$ started to enit electrons at the fields of 1.9 .1 .6 and $1.1 \mathrm{~V} / \mu \mathrm{m}$, respectively. but the emissions were not homogenous. As the applied field was increased, more uniforn emission occurred on a phosphor screen in all cases. The phosphor screens became quite homogenous over the all area when the applied fields were 4.0. 3.4 and $3.1 \mathrm{~V} / \mu \mathrm{m}$. respectively (see Figure 5). very homogeneous emissions may be due to the uniformity in height and diameter, high quality and well alignment of the tubes.

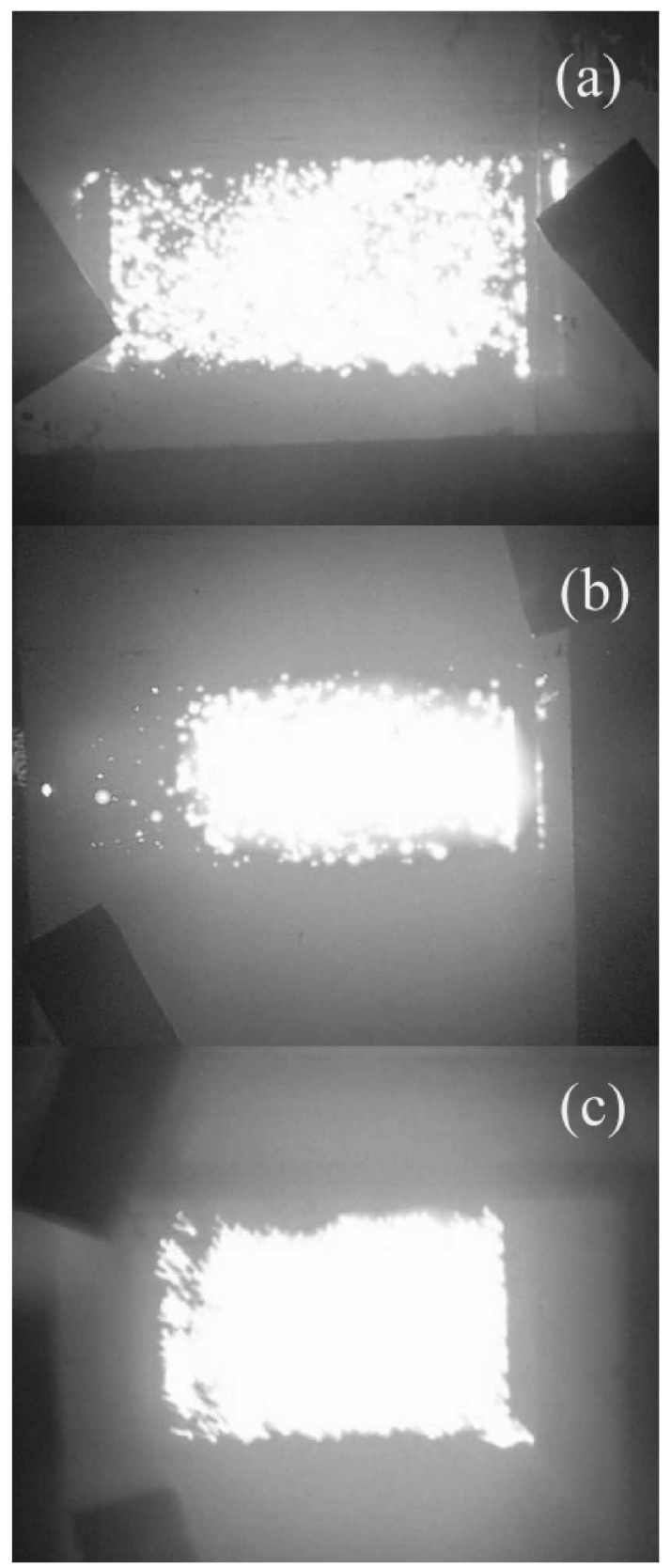

Figure 5. Emission pattents of the CNTs fabncated by $\mathrm{CO}$ disproportionation at (a) 500 , (b) 550 , (c) $600^{\circ} \mathrm{C}$ by applying 4.0 , 3.4 and $3.1 \mathrm{~V} / \mu \mathrm{m}$, respectively.
The CNTs studied here are fabricated relatively at low temperature but they show good field emission properties. These could be due to $\mathrm{CO}$ used as the precursor. When $\mathrm{CO}$ is disproportionated on the catalyst surface. only $\mathrm{C}$ and $\mathrm{CO}_{2}$ are produced. The byproduct. $\mathrm{CO}_{2}$ is a very stable gas and will desorb from the surface without further reaction. Therefore, pure carbon will be provided in the process of growing carbon nanotubes. Anyway, many hydrocarbons have been used as precursors. For using hydrocarbons as a precursor. there is no guarantee to provide pure carbon in the fabrication of CNTs. For example. the decomposition process of $\mathrm{C}_{2} \mathrm{H}_{2}$ is much complicated and some intermediate species like $\mathrm{CH}$ or $\mathrm{C}_{2} \mathrm{H}$ can be involved in the process of growing carbon nanotubes. In this case, dangling bonds due to hydrogen atoms could be made in carbon nanotubes. These hydrogen atoms will be removed by further decomposition during fabrication or annealing but the defects due to these hydrogen atoms in the crystalline structure of carbon nanotubes will not be recovered completely.

As discussed earlier, the AAO templates were not deformed or cracked when CNTs were fabricated at $600^{\circ} \mathrm{C}$ or at lower temperature. In a practical aspect. low fabrication temperature such as $500^{\circ} \mathrm{C}$ is very important since it is lower than the melting point of soda lime glass $\left(550^{\circ} \mathrm{C}\right.$ ), which is commonly used as a low-cost substrate for display panel $^{26} \mathrm{By}$ using lydrocarbons as the precursor. it is difficult to fabricate CNTs directly on the soda lime glass at lower temperature than its melting point because CNTs could grow at least $600^{\circ} \mathrm{C}$ or higher temperature.

\section{Conclusions}

In conclusion, the CNTs fabricated on AAO templates by disproportionation of $\mathrm{CO}$ have excellent field emission properties like uniform emission. high enhancement factor, and relatively low turn-on voltage. This may be due to high quality and vertical aligmment of the CNTs fabricated on AAO templates by disproportionation of $\mathrm{CO}$. Low fabrication temperature such as $500^{\circ} \mathrm{C}$ could make it possible to use soda lime as the substrate for display panels.

Acknowledgements. This work was supported by the BK2l program, the Ministry of Commerce, Industry and Energy, and the KOSEF through $\mathrm{CNNC}$.

\section{References}

1. de Heer. W. A.: Chatelain. A.: Ugarte. D. Science 1995. 270. 1179.

2. Jung, K: Jang. S.; Vittal, R; Kim. D.: Kim, K: Bull. Korean Chent Soc. 2003, 2t. 1501

3. Lee. C. J.; Park, J; Kang, S. Y.; Lee, J. H. Chem. Phys. Lett. 2000. 326. 175.

4. Saito. Y.: Uemura. S. Carbon 2000. 38. 169

5. Fransen. M. T.: van Rooy. Th. L.: Kruit. P. Appl. Suf. Science? 1999. $1+6,312$

6. Sharma. R. B.: Tondare. V. N.: Joag. D. S.; Govindaraj, A.: Rao, C. N. R. Chem. Phys Lett. 2001, 3H+. 283.

7. Jeong. S. H.: Hwang. H. Y.: Lee. K. H. Teong. Y. App. Plys. Lett 
2001. 78. 2052

8. Davydov. D. N.: Sattari. P. A.: AlMawlawi. D.: Osika. A.: Haslet. T. L.: Moskovits, M. J. Appl. Phys. 1999. 86, 3983.

9. Yuan. Z. H.: Huang. H.: Dang. H. Y.: Cao. I. E.: Hu, B. H. Fan. S. S. App. Phss. Lett. 2001, 78.3127

10. Chen. P.: Wu. X.: Lin. J.: Li. H.: Tan. K. L. Carbon 2000. 38.139

11. Chen. P.: Zhang. H. B.: Lin. G. D.: Hong. Q.: Tsai. K. R. Carbon 1997.35. 1495 .

12. Kitivanan. B.: Altarez. W. E.: Harwell. J. H.: Resasco, D. E. Chem. Plos. Lett 2000, 317, 497.

13. Marta, G.: Marchese, L.: Arena. F.: Parmaliana. A.: Coluccia, S. Topics in Catahsis 1 1994. 63.

14. Lee. J. S.: Kim. H.: Suh. J. S. Smih. Metals 2001. 124. 307.

15. Lee. J. S.: Sul. J. S. J. Appl. Phis. 2002. 92. 7519.

16. Masuda H: Sotoh. M. Jpn. J. Appl. Phns, 1996,35 L126.

17. Sul, I. S. Lee, I. S. Appl Ph:s. Lett 1999. 75, 2047.
18. Yoon. C.: Suh. J. S. Bull. Koran Chem Soc. 2002. 23.1519.

19. Lee. T. S.: Gu. G. H.: Kim. H.: Jeong. K. S.: Bae. J.: Suh. I. S. Chent Mater. 2001. 13. 2387.

20. Tuinstra. F, Koenic J. L. J. Chent. Plns. 1970, 53.1126.

21. Endo. M.: Kim, Y. A.; Fukai, Y.: Hayashi, T: Terrones, M.: Terrones. H.: Dresselhaus. M. S. Appl. Plys. Lett. 2001. 79. 1531.

22. Fowler. R. H.: Nordheim. L. W. Proc. R. Soc. London. Sen A 1928. 119.173.

23. Xu. X; Brandes, G. R. Appl. Phws. Lett. 1999, 74. 2549.

24. Nilsson. L.: Groening, O.: Emmenegger, C.: Kuettel, O.: Schaller, E.; Schlapbach. L.; Kind. H.: Bonard. J.-M.: Kem. K. Appl. Phws Lett. 2000. 76. 2071 .

25. Suh. T. S.: Jeong. K. S.: Lee. T. S.: Hant. I. Appl. Phus. Lett. 2002. 80.2392.

26. Lee. C. J.; Park. J.: Han. S.: Ihm. J. Chem. Phrs Lett. 2001, 337. 398. 